\title{
Optimization of Fuel Cell Hybrid Electric Vehicle Parameters.
}

\author{
Zahraa Salam Dawood ${ }^{1}$,Sadiq M. Ihmood ${ }^{2}$
}

1 MSc student Mechanical Engineering/ University of Thi Qar

2 Mechanical Engineering/ University of Thi Qar

\begin{abstract}
The emission that caused by fossil fuel and the constantly increasing pollution rates made the engineers and researchers focus on using hydrogen as a fuel instead of fossil fuel. Fuel cells are one of the technologies that are widely explored all over the world. Fuel cell vehicles are environmentally friendly and use hydrogen as fuel and generate zero emissions. Optimization strategies is the best way for identify the best solution to the design issue. In this work we will use particle swarm optimization and genetic algorithm to optimize the obtained model. The result show that the best choice between the three accebtable cases is case 5 because in this case the fuel consumption is $2.7668 \mathrm{Litter} / 100 \mathrm{~km}$ which is lower than the fuel consumption
\end{abstract}

Keywords: Fuel cell, HEV, PSO, Genetic algorithm.

\section{Introduction}

Recently, the need to use a new source of energy in transportation instead of using fossil fuels that causes environmental pollution and emissions, such as NOx, CO, $\mathrm{CO} 2$, has emerged [1]. Perhaps the most difficult environmental problem to be solved is the greenhouse effect that is caused primarily by carbon dioxide emissions. Therefore, there was a collaborative effort between the government and industry to develop fuel cell cars. Hydrogen is the best choice to use it as a new energy source. Like electricity, hydrogen can provide a high amount of energy, hydrogen storage is the one of the most important research issues in the development of FCVs. And the reason for the need for a hydrogen tank, because hydrogen possesses a low energy density and it is also one of the lighter elements in the periodic table. The economy of hydrogen need two kinds of systems for storage hydrogen, one of them for transport and the other for fixed implementations [2]. tremendous concerns have been raised by discovering and reproducing the high hydrogen absorption capacity in carbon nanotubes and other lowdimensional carbon materials [3]. HFCVs are electric vehicles that use an electrochemical process to convert hydrogen into electricity. Fuel cell vehicles are electric vehicles that run on batteries and fuel cells. Like electric vehicles, HFCVs are zero-emission vehicles because they do not emit carbon dioxide emissions, nitrogen oxides or other pollutants directly, which leads to calls for the adoption of these vehicles more widely[4,5]. Commercially available HFCVs from Honda, Toyota and Hyundai use electrolytic polymer membrane fuel technology (PEMFC). (PEMFC) is a very common type of fuel cell for transportation implementations. The fuel cell is a device used to restore the charge of the battery and super capacitor [6].In order to evaluate the performance of vehicles the driving cycles was produced by many country. we use UDDS driving cycle for the test of emission and fuel cell consumption. In the UDDS cycle The starting stage is cold and this transient stage is followed by several speed peaks that begin from rest. The strategies of optimization are considered as a sturdy tool for determine the better probable solutions for the problems of the design, especially When standard orders do not extend an ideal, immediately Recognition the solution [7]. These methods have confirmed that they are very effective in producing hybrid power generation groups and related the strategies to manage the energy. In this study we use the (PSO) and (GA) to optimize the model parameter. However, each of (PSO) version has a various merit to a various complicated ideal issue.

\section{Vehicle components}

The fuel cell vehicle components are shown in Fig. 1. The system of power consist of a fuel cell such as (PEMFC) which it fueled by pressurized hydrogen ,the Maxwell supercapacitor and a nickel metal hydride Ovonic battery. All of the above components are joined together in parallel The force is withdrawn according to a suitable domination strategy [6]. The electric motor and The power system are coupled by DC/DC adapter and a $\mathrm{DC} / \mathrm{AC}$ invertor. in order to feed the electric motor the DC / $\mathrm{AC}$ inverter used to converts the current from (DC) into (AC) [8]. The use of fuel cell is to Start the electric motor and restore the charge of supercapacitor or the battery when the energy that was stored becomes less than the minimum. furthermore, the super capacitor and the battery are restored their charge by regenerative of braking.

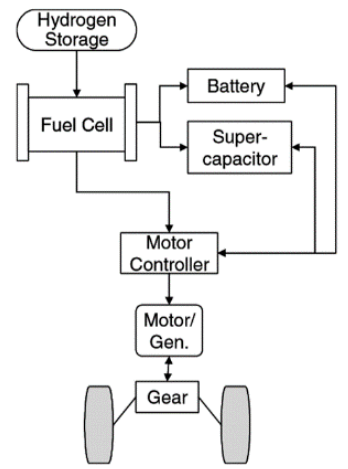

Fig 1. Vehicle configuration [6] 


\subsection{A polymer electrolyte fuel cell (PEMFC)}

(PEMFC) is an electrochemical instrument that produce electricity from the transform of the chemical energy which is used to power an electric motor with water and heat being a by-product only [9]. Initially developed as part of a program with the U.S. Navy Ship Office and the indicative legions of the U.S. Army to provide portable power to individuals in the arena [10]. The membrane electrode group is the primary component of a fuel cell that helps produce the electrochemical reactions needed to separate electrons and consists of a polymer electrolyte membrane (PEM). Hydrogen is supplied to a negative electrode(anode), where it is activated on a catalyst, which leads to the release of electrons. These electrons travel from the anode to the cathode to generate electricity [4]. In the cathode, protons and oxygen from the air and free electrons interact to form water as a byproduct of the process.

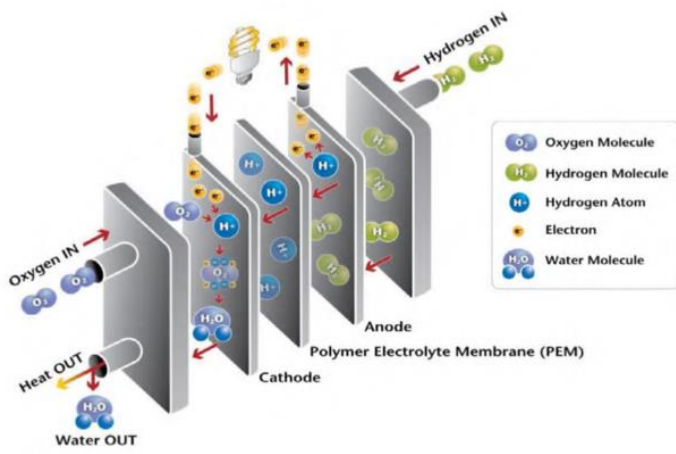

Fig 2. Schematics of PEMFC [9]

\section{The production of hydrogen}

Hydrogen is one of the elements that are abundance in the crust of earth. But hydrogen is always found in a combination with another elements. So to produce hydrogen from other sources that contain it electricity and heat can be used[3]. Biomass, natural gas, water or coal can be used to produce hydrogen. Currently, 95\% of hydrogen that is used all comes from fossil fuels through the vapor reform of the partial oxidation of heavy hydrocarbons or coal and the natural gas. Water can be used to produce hydrogen and that by dividing it by different procedures, such us electrolysis, image electrolysis, disintegration at high temperatures, and the water photosynthetic biological division. Hydrogen produced from water electrolysis obtain efficiency of $75 \%$, however, currently the hydrogen cost is Much higher than the cost of fossil fuels. Because the water needs a temperatures of about $2000^{\circ} \mathrm{C}$ for its immediate thermal division and produces a rapid blend of oxygen and hydrogen. In order to minimize the temperatures and produce oxygen and hydrogen in detached steps a number of thermochemical cycles have been used. The one that draw the most attentiveness involved hydrogen iodide and sulfuric acid at $450{ }^{\circ} \mathrm{C}$ and $850{ }^{\circ} \mathrm{C}$ respectively. The designs that included in the following generation of fission reactors can supply the requisite heat, yet the properties of some of critical material should be met the wanted steadiness beneath sulfuric acid and hydrogen iodide operating conditions. For safety reasons, it is necessary to have agreeable extended line to transfer heat which it about $(1 \mathrm{~km})$, for this reason the chemical factory for produce hydrogen is placed afar from the reactor [11]. Electricity that comes from the sources of the renewable energy like waves, solar, wind and tides may provide the necessities of the local hydrogen, however, they will certainly not fulfill the needed global magnitude of hydrogen for their common use as a new source of energy [12].

\section{Driving cycles}

The driving cycle is a typical driving style. In order to evaluate the vehicles performance, driving cycles are produced by various organizations and countries. The acceleration is supposed to be constant through the time step. and because of that the velocity is a linear function of time through the time step. That is because acceleration and speed are recognized for every point of time. several of driving cycles are derived theoretically which is favored in the European Union, while others are immediately measure of the represented style of driving.

\section{Emissions measurement by using driving cycles}

Some of the pollution in air are comes from the vehicles on the road and that because of combustion and other operations. In accordance with European Union instruction, emissions of carbon monoxide $(\mathrm{CO})$, nitrogen oxide (NOx), and emissions of volatile organic compounds (VOCs) and particulate matter (PM) are organized, So is the case for emissions of evaporation from volatile organic compounds[13]. Many informal gas pollutants are also emitted, but are generally described in less detail. the United States used FTP-75 cycle to test the certificate of the emission for vehicles like light trucks and cars. introduce Federal Supplementary Test Procedure (SFTP) "SC03" to represent the load of the motor and emissions that related to the use of the units of air conditioning in approved vehicles during the test of FTP 75 cycle. the European Union, the law requires type approval emissions tests for all models of new engines and light vehicles that used in heavy vehicles. The emissions from exhaust of the vehicle are variable by nature, thus to assure that the test of emission can be reproduced the better way that to carry it out under standard conditions of the laboratory [14]. Pollutant collection and analysis procedures are detailed in the statute. A dynamic energy absorption meter is used to test vehicles, while heavy engines are run on a test bed. As for Japan, in order to obtain the emissions and economy certification of fuel they used for light engines the 13 style cycle for test, as for heavy vehicles 10-15 style cycle is used.

\section{UDDS driving cycle}

this cycle was expansion to characterize the road of urban In the beginning of seventies. In this cycle The starting stage is cold and this passing stage is followed by several speed peaks that begin from rest. UDDS cycle is a emulation to the track of urban driving which the long is about $12.1 \mathrm{~km}$ and to accomplish it that takes about 1,369 seconds. this cycle contain numerous stops and fulfill a top velocity of about $91.3 \mathrm{~km} / \mathrm{h}$. The cycle average velocity is about $31.5 \mathrm{~km} / \mathrm{h}$. There are two stages in this cycle 
The first one continue to 505second with average velocity of about $41.2 \mathrm{~km} / \mathrm{h}$ and about $5.8 \mathrm{~km}$ while for the second it takes 864 second [15].

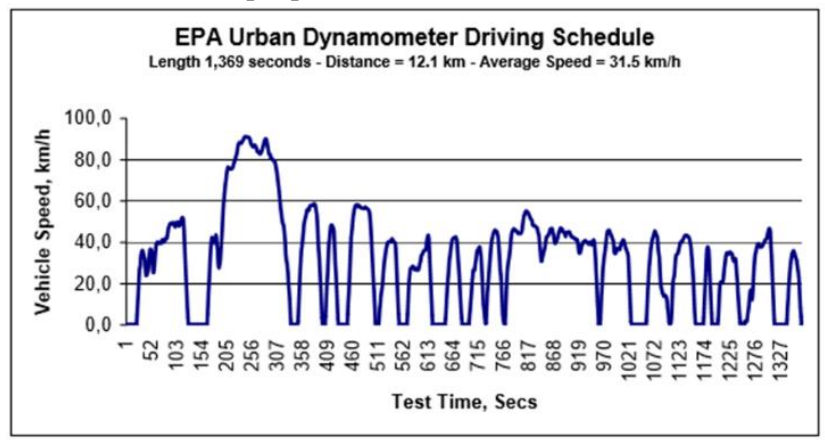

Fig 3. (UDDS) cycle [15]

\section{Optimization}

the maximum or minimum value for a process or function can be determined by using the optimization techniques [16]. Optimization can be used in a lots of fields like engineering, alchemy, physics and economics which the main purpose is to raise effectiveness of the electronic, production or another process. This method has confirmed to be greatly effective in creating the generating sets of hybrid power and related strategies of energy management. Hence, many strategies can be envisioned, however those that we have seen in nature each day, and confirm effective through the fastness of the types practiced by them, indeed present a wide set of solutions. Multi-purpose optimization works requires the preference among space of function and space of fitness and that comprise numerous topical functions that derive inputs of the space of parameter itself.

\subsection{Genetic algorithm (GA)}

It is a searching operation for the maximum or minimum target functions and fulfillment some restrictions at the same time some restrictions on the variables of design and choosing the better arrangements that produces from every generation [7].

\section{2. particle swarm optimization (PSO)}

The particle swarm optimization theory was developing quickly. Numerous implementations various problems have used the PSO [17]. PSO is a collective messy style, a repetition method, with a concentration on collaboration; this method is partly random and with no identification. PSO was primarily presenting by Eberhart and Kennedy. After the presenting of PSO, the potential and simplicity of the algorithm succeeded in fulfillment a highly effective study for close perfect problems solution even those in a very difficult research space, and it catch the attention of numerous researchers trying to resolve and develop it, as well as those ones who intended to implement it.

The PSO algorithm is a synthetic intelligence technique depend on notices of gregarious behavior of fish and bird flock. Every solution is considered as a bird named a particle and all these particles have a value of fitness. The topical function can be using to count the values of fitness .All molecules maintain their better single performance as well as know the better performance for their group.The particales control their speed, taking into account their better performance and as well as looking for the better particle that have better performance .It has been observed that the behavior of individuals belonging to a swarm adheres to basic rules such as matching the speed of the nearest neighbor and acceleration from a distance [18].

The particle swarm optimization algorithm acts at one time on preserving the solutions of numerous candidate in the area of search. through every repetition of the algorithm, every solution of the candidate is estimated by improved the target function, and find out the suitability of this solution. We can considered every solution of the candidate as a particle by the scene - determining the max or min substantive function. In PSO, a swarm of individuals communicates either directly or indirectly with other research directions (gradients).

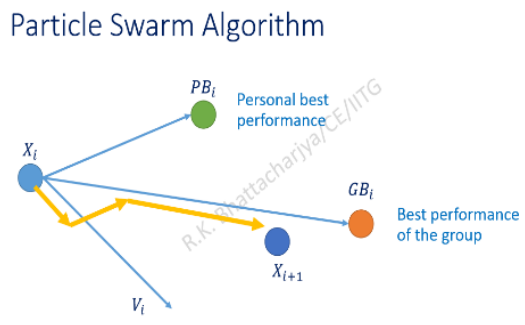

Fig 4. PSO algorithm [25]

Particle swarms are somehow tightly linked to cellular automation :

a) The modernizations of solo cell are made in parallel.

b) Every value of the new cell rely just on the outdated values of the cell and neighbors to it.

c) The same rules are used for the modernization of the whole cells

The particles transition across the area of search according to the rules for updating their speed and coordinates too, defined as

$\mathrm{x}_{i}(\mathrm{t}+1)=\mathrm{x}_{i}(\mathrm{t})+\mathrm{v}_{i}(\mathrm{t}+1)$

$\mathrm{v}_{i}(\mathrm{t}+1)=\mathrm{v}_{i}(\mathrm{t})+\mathrm{C}_{1} \mathrm{r}_{1}\left(\mathrm{~PB}_{i}-\mathrm{x}_{i}(\mathrm{t})\right)+\mathrm{C}_{2} \mathrm{r}_{2}\left(\mathrm{~GB}_{i}-\mathrm{x}_{i}(\mathrm{t})\right)$

Where

$\mathrm{x}_{\mathrm{i}}(\mathrm{t})$ : The initial position of the particle

$\mathrm{x}_{\mathrm{i}}(\mathrm{t}+1)$ : The new position of the particle

$v_{i}(t)$ : The initial velocity

$\mathrm{v}_{\mathrm{i}}(\mathrm{t}+1)$ :The new velocity

$\mathrm{C}_{1}$ and $\mathrm{C}_{2}$ :The coefficients of acceleration

$\mathrm{r}_{1}$ and $\mathrm{r}_{2}$ : The random vector

$\mathrm{PB}_{\mathrm{i}}$ : Personal best performance

$\mathrm{GB}_{\mathrm{i}}$ : Best performance of the group

\section{PSO variation}

Several variations were advanced to amelioration the rapprochement speed and fineness of the solution that PSO get it. A numeral of control parameters are affect the variance, which are the problem dimensions, the particles number (the volume of the swarm), the coefficients of acceleration (the acceleration factor $C_{1}$ and $C_{2}, r_{1}$ and $r_{2}$ which are the random vector, the random effect control), inertia of weight, the neighborhood volume, the repetitions 
number, and the random amounts that It measures the contribute of the Knowledge and gregarious component. The inertia weight factor was not primarily a section of the algorithm of PSO, however it was a subsequent modulation which turn into acceptable in general.

In addition, several PSO variances do not contain one global side better for the algorithm, they use instead many of the better global which are participation by detached Secondary groups of particles. There are numerous variances. Whole check of numerous of these modulations to the algorithm of PSO. Here are the main variation of PSO:

\subsection{The clamping velocity}

The fixation of velocity will dominate the global reconnoitering of the particle. beneath most of settings, the swarm can be spread out over a so wide zone in the space of search, Which leads in so high velocity of particle. Performance can suffer if Vmax is set incorrectly. Clamping velocity did not affect the particle place. That just minimize the magnitude of the speed of the step. alterations in the orientation of research not just can industrialize particles for best reconnoitering,furthermore, they have passive impacts and unable to get the optimum value. The following equations are used for prepare the maximum and minimum of solution speed

$$
\begin{aligned}
& \mathrm{v}(\max , \mathrm{j})=\delta(\mathrm{x}(\max , \mathrm{j})-\mathrm{x}(\min , \mathrm{j})) \\
& \mathrm{v}(\min , \mathrm{j})=\delta(\mathrm{x}(\min , \mathrm{j})-\mathrm{x}(\max , \mathrm{j})) \\
& \text { Where: }
\end{aligned}
$$

$\mathrm{x}(\max , \mathrm{j})$ : The maximum location of the particle in $\mathrm{j}^{\mathrm{th}}$ dimension

$x(\min , j)$ : The minimum location of the particle in $j^{\text {th }}$ dimension

$\delta$ : The constant factor from 0 to 1 .

Two methods were developed to control the growth of speeds

1. Dynamically modified inertia factor

2. Coefficient of constriction.

\subsection{Inertia of Weight}

This is a technique used to govern squadron's reconnoitering and utilization capabilities, and also to get rid the requirement for clamping velocity. It is governs the values of current speed that impacts the speed of the following time stride. This technique was presenting by Eberhart and Shi. With the use of the inertia weight, Eqs (1) and (2) will became as follow:

$$
\begin{aligned}
& \mathrm{x}_{i}(\mathrm{t}+1)=\mathrm{x}_{i}(\mathrm{t})+\mathrm{v}_{i}(\mathrm{t}+1) \\
& \mathrm{v}_{i}(\mathrm{t}+1)=\mathrm{wv}_{i}(\mathrm{t})+\mathrm{C}_{1} \mathrm{r}_{1}\left(\mathrm{~PB}_{i}-\mathrm{x}_{i}(\mathrm{t})\right)+\mathrm{C}_{2} \mathrm{r}_{2}\left(\mathrm{~GB}_{i}-\mathrm{x}_{i}(\mathrm{t})\right)
\end{aligned}
$$

The larger value will facilitate the exploration process, but the smaller amounts will enhance the utilization, and several of researchers have developed an use of inertia weight

\section{3 Coefficient of Constriction}

Kennedy and Clerc studied particle swarm optimization as a category of controllable dynamic systems by choosing coefficient parameters in the system equation. The coefficient of constriction is applied on both conditions of the velocity equation. Clerc clarifys that systolic particle swarm optimization able to rapprochement without the use of max velocity

$$
\begin{aligned}
& \mathrm{v}_{i}(\mathrm{t}+1)=\mathrm{k}\left(\mathrm{v}_{i}(\mathrm{t})+\mathrm{C}_{1} \mathrm{r}_{1}\left(\mathrm{~PB}_{i}-\mathrm{x}_{i}(\mathrm{t})\right)+\mathrm{C}_{2} \mathrm{r}_{2}\left(\mathrm{~GB}_{i}-\mathrm{x}_{i}(\mathrm{t})\right)\right) \\
& \text { Where }
\end{aligned}
$$

$$
\begin{aligned}
& \mathrm{k}=2 /\left|2-\mathrm{C}-\operatorname{sqrt}\left(\mathrm{C}^{2}-4 \mathrm{C}\right)\right| \\
& \mathrm{C}=\mathrm{C}_{1}+\mathrm{C}_{2}
\end{aligned}
$$

The mathematical modeling of Fuel Cell HEV consists of two objective functions:

$F_{1}(x)$ : Fuel Consumptions FC (Litter/100 km).

$\mathrm{F}_{2}(\mathrm{x})$ : State of Charge (SOC) of the battery

$\mathrm{x}$ : represents the optimization variables which is:

mc_trq_scale : The factor of torque scaling of the motor. battery.

cs_charge_pwr : Power required to charge the

cs_hi_soc : The allowable high state of charge.

cs_lo_soc : The allowable low state of charge.

The above objective functions are conflicting with each other, therefore to find the tradeoff solution, these multi objective functions are converted to a one target function by use the method of weighted sum. Every target function in this method is doubled through the weight that provided by a user.

$$
\mathrm{F}(\mathrm{x})=\mathrm{w}_{1} * \mathrm{~F}_{1}(\mathrm{x})+\frac{w_{2}}{F_{2}(x)}
$$

Where

$\mathrm{F}(\mathrm{x})$ : is the function of fitness.

$\mathrm{W}_{1}, \mathrm{~W}_{2}$ are the weights for each target function.

Many researchers select the weights based on expertise and solving the problem yielding a single solution. In order to achieve numerous solutions, the issue should be resolve many times through various weight group. Other researchers select the weights randomly for each solution. In this work to find the appropriate weight values for each solution a genetic algorithm is used. The procedure of this work is illustrated in Fig. 6

\section{Validation of the work}

To confirm the correctness of the work, Ref[19] has been re-implementation in the manner used in this research. The following results were obtained: Table 1 Comparison results.

\begin{tabular}{|c|c|c|}
\hline \multirow{3}{*}{ Current Work } & fc_eff_scale & 1.95256 \\
\cline { 2 - 3 } & mc_eff_scale & 1.214563 \\
\cline { 2 - 3 } & ess_module_num & 30 \\
\cline { 2 - 3 } & Fc & 2.4041 \\
\hline M.Kandi-D Ref [19] & Fc & 3 \\
\hline
\end{tabular}

It's obvious that current work gives better results, since there is reduction in fuel consumption about $19.863 \%$ as shown in Fig. 5. 


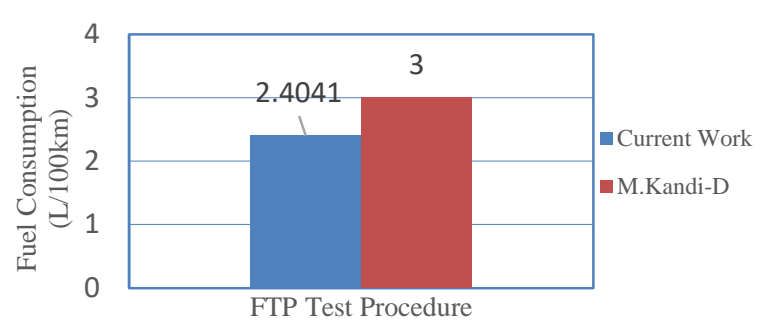

Fig. 5 Comparison results of fuel consumption.

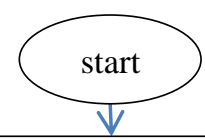

Initialize position $x_{i j}^{0} \mathrm{c} 1, \mathrm{c} 2$, velocity $V_{i j}^{0}, \mathrm{D}=\max$. no of dimensions, $\mathrm{P}=\max$. no of particles, $\mathrm{N}=$ max.no of

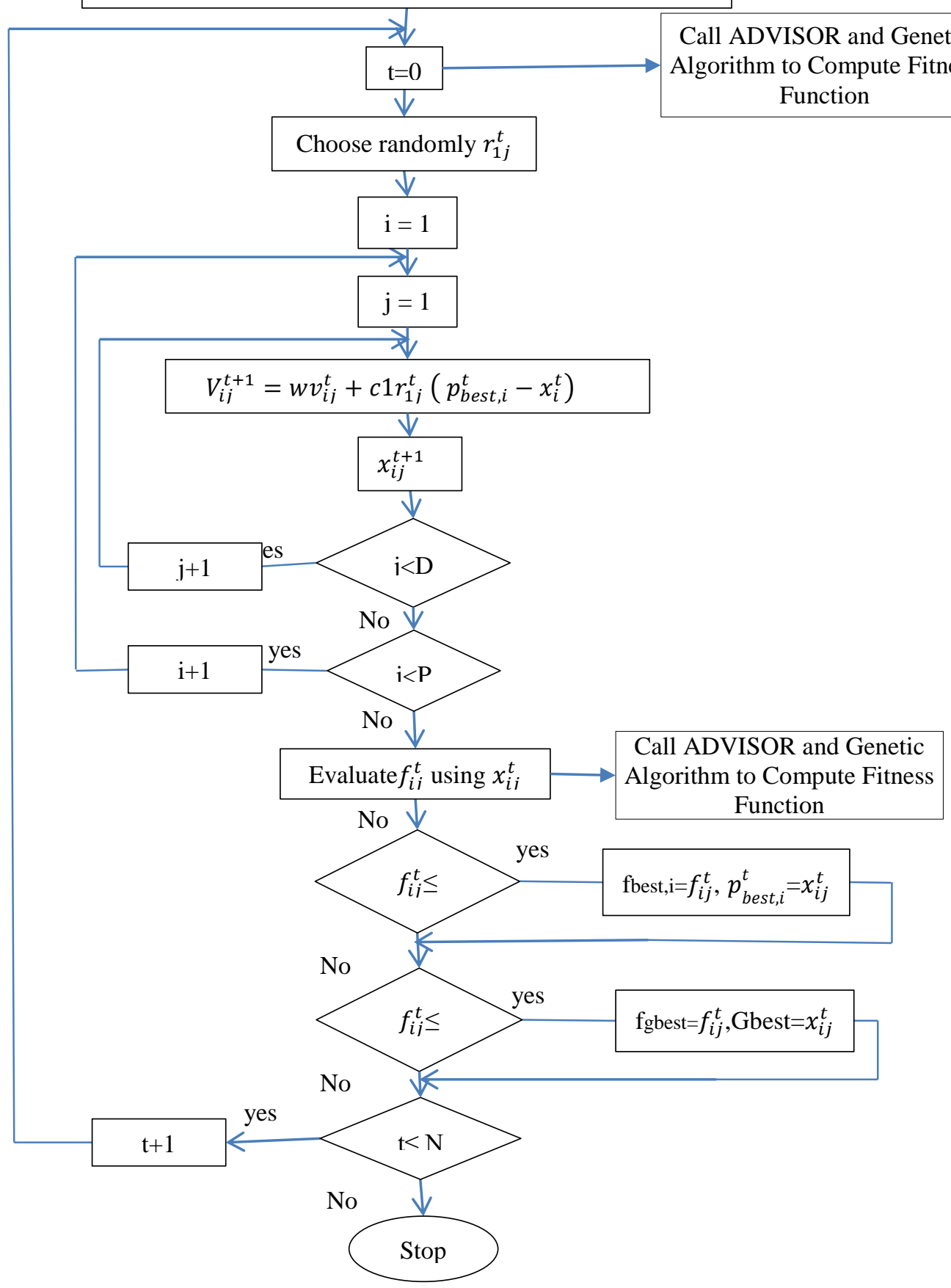

Fig 6. Flow chart of the current work 


\section{Results and Discussions}

Analysis of Variance (ANOVA) is a hypothesistesting technique which is use to analyze the effect of design variables on fuel consumption and state of charge.

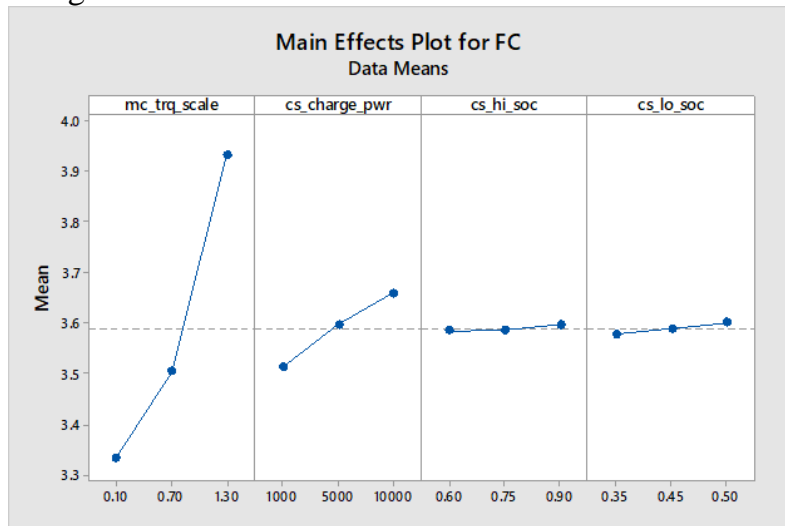

Fig. 7 Main Effects Plot for fuel consumption

It is evident from Fig. 7 that fuel consumption increases with all variables, but the most influential variables on fuel consumption mc_trq_scale and cs_charge_pwr. While the other two variables cs_hi_soc and cs_lo_soc have less impact on fuel consumption. When mc_trq_scale and cs_charge_pwr are increased, the fuel consumption will increase accordingly, because the required torque is high to meet the power demand and battery charging.

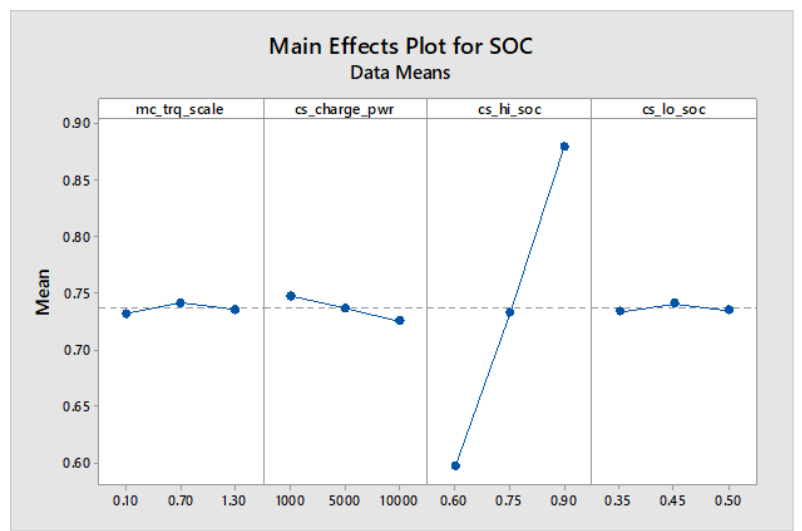

Fig. 8 Main Effects Plot for state of charge

It is obvious from Fig. 8 that the state of charge of battery is greatly affected by the variable cs_hi_soc, if cs_hi_soc $=0.6$, this means the current state of charge SOC will start from $60 \%$ )i.e. $60 \%$ of the battery capacity will be used). Likewise if cs_hi_soc $=0.9$, the current state of charge SOC will start from $90 \%$ )i.e. $90 \%$ of the battery capacity will be used). It is worth mentioning that the controller will prevent the battery from charging when $\mathrm{SOC}=$ cs_hi_soc.

When SOC is high, the required cs_charge _pwr is low because there is no urgent need to charge the battery. If the battery's SOC is low then there is a need to charge the battery, so the cs_charge _pwr should be high. Finally, the variables cs_lo_soc mc_trq_scale have no apparent effect on the SOC.

In this work particle swarm optimization and genetic algorithm are used to get the optimum operating points for the entire driving cycle for 5 cases to find the best fuel consumption. In each case the solution will continue until the best cost function is fixed at a certain value for several successive generations as described in fig 9. Table 2 show the value of some parameters and fuel consumption for each case.

Table 2 The value of some parameters and fuel consumption for each case

\begin{tabular}{|c|c|c|c|c|c|c|c|}
\hline & $\begin{array}{c}\text { mc_trq_ } \\
\text { scale }\end{array}$ & $\begin{array}{c}\text { cs_charge } \\
\text { _pwr }\end{array}$ & $\begin{array}{c}\text { cs_hi } \\
\text { _soc }\end{array}$ & $\begin{array}{c}\text { cs_lo } \\
\text { _soc }\end{array}$ & $\begin{array}{c}\text { Fuel } \\
\text { consu } \\
\text { mption }\end{array}$ & SOC & Notes \\
\hline Case 1 & 1.025 & 7399.29 & 0.806 & 0.438 & 3.66 & 0.790 & \\
\hline Case 2 & 0.319 & 6255.93 & 0.999 & 0.494 & 3.25 & 0.977 & $\begin{array}{c}\text { Reject since } \\
\text { hi_soc large } \\
\text { than upper } \\
\text { limit 0.9 }\end{array}$ \\
\hline Case 3 & 0.057 & 10484.77 & 1.009 & 0.494 & 2.76 & 0.867 & $\begin{array}{c}\text { Reject since } \\
\text { hi_soc large } \\
\text { than 1 }\end{array}$ \\
\hline Case 4 & 0.278 & 7216.29 & 0.879 & 0.426 & 3.26 & 0.855 & \\
\hline Case 5 & 0.055 & 4360.68 & 0.816 & 0.425 & 2.76 & 0.745 & Best Solution \\
\hline
\end{tabular}

Case two and case three are rejected because in case two and three the cs_hi_soc is 0.999180 and 1.009021 which is higher than the upper limit 0.9 as shown in table 2 . The best choice between the three acceptable cases is case 5 because in this case the fuel consumption is $2.7668 \mathrm{Litter} / 100 \mathrm{~km}$ which is lower than the fuel consumption.

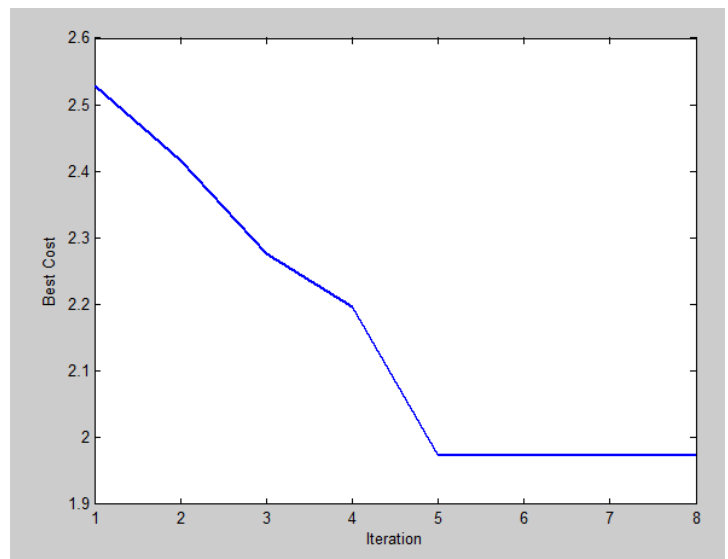

Fig. 9 The optimization process history (the best objective value in the population vs. generation number) for the UDDS driving cycle. 


$\begin{array}{ll}\text { GLOSSARY } & \text { Hybrid fuel cell vehicles } \\ \text { HFCVs } & \text { Fuel cell vehicles } \\ \text { FCVs. } & \text { Polymer electrolyte membrane fuel cell } \\ \text { PEMFC } & \text { Urban dynamometer driving schedule } \\ \text { UDDS } & \text { Particle swarm optimization } \\ \text { PSO } & \text { Genetic algorithm } \\ \text { GA } & \text { Alternating current } \\ \text { AC } & \text { Direct current } \\ \text { DC } & \text { Polymer electrolyte membrane } \\ \text { PEM } & \text { Carbon monoxide } \\ \text { CO } & \text { Nitrogen oxide } \\ \text { NOx } & \text { Volatile organic compounds } \\ \text { VOCs } & \text { Particulate matter } \\ \text { PM } & \text { Supplementary federal test procedure } \\ \text { SFTP } & \text { Personal best performance } \\ \text { PB } & \text { Best performance of the group } \\ \text { GB } & \text { Analysis of Variance } \\ \text { ANOVA } & \text { The factor of torque scaling of the } \\ \text { mc_trq_scale } & \\ \text { motor. } & \\ \text { cs_charge_pwr } & \text { Power required to charge the battery. } \\ \text { cs_hi_soc } & \text { The allowable high state of charge. } \\ \text { cs_lo_soc } & \text { The allowable low state of charge. } \\ \text { FC } & \text { Fuel consumption } \\ \text { SOC } & \text { State of charge }\end{array}$

\section{Reference}

[1] Åhman, M. (2001). Primary energy efficiency of alternative powertrains in vehicles. Energy,26(11), 973989.https://doi.org/10.1016/S03605442(01)00049-4

[2] Ross, D. K. (2006). Hydrogen storage: The major technological barrier to the development of hydrogen fuel cell cars. Vacuum, 80(10), 1084-1089. https://doi.org/10.1016/j.vacuum.2006.03.030

[3] Cheng, H. M., Liu, C., Fan, Y. Y., Li, F., Su, G., Cong, H. T., He, L. L., \& Liu, M. (2000). Synthesis and hydrogen storage of carbon nanofibers and singlewalled carbon nanotubes. Zeitschrift Fuer Metallkunde/Materials Research and Advanced Techniques, 91(4), 306-310.

[4] Manoharan, Y., Hosseini, S. E., Butler, B., Alzhahrani, H., Senior, B. T. F., Ashuri, T., \& Krohn, J. (2019). Hydrogen fuel cell vehicles; Current status and future prospect. Applied Sciences (Switzerland), 9(11). https://doi.org/10.3390/app9112296

[5] Eberle, U., Müller, B., \& Von Helmolt, R. (2012). Fuel cell electric vehicles and hydrogen infrastructure: Status 2012. Energy and Environmental Science, 5(10), 8780-8798. https://doi.org/10.1039/c2ee22596d

[6] Paladini, V., Donateo, T., de Risi, A., \& Laforgia, D. (2007). Super-capacitors fuel-cell hybrid electric vehicle optimization and control strategy development. Energy Conversion and Management, 48(11), 30013008. https://doi.org/10.1016/j.enconman.2007.07.014 [7] Walker, P. D., Abdul Rahman, S., Zhu, B., \& Zhang, N. (2013). Modelling, simulations, and optimisation of electric vehicles for analysis of transmission ratio selection. Advances in Mechanical Engineering,2013. https://doi.org/10.1155/2013/340435 [8] Briguglio, N., Andaloro, L., Ferraro, M., \& Antonucci, V. (2011). Fuel Cell Hybrid Electric Vehicles. Electric Vehicles Â€“" The Benefits and Barriers, May 2015. https://doi.org/10.5772/18634

[9] Üçok, Mehmet Doğan, (IICEC/SABANCI UNIVERSITY). (2019). Iicec Energy and Climate Research Paper Hydrogen Fuel Cell Vehicles. August.

[10] Cook, B. (2002). Introduction to fuel cells and hydrogen technology. Engineering science and Education Journal, 11(6), 205-216. https://doi.org/10.1049/esej:20020601

[11] Turner, J. A. (2004). Sustainable hydrogen production.Science,305(5686),972-974.

https://doi.org/10.1126/science.1103197

[12] Turner, J. A. (1999). A realizable renewable energy future.Science,285(5428),687-689. https://doi.org/10.1126/science.285.5428.687

[13] Zannikos, F. E. (2018). Vehicle emissions and driving cycles: comparison of the Athens driving cycle (ADC) with ECE-15 and European driving cycle (EDC). Global NEST JournalGlobal NEST: The International Journal, 8(3), 282-290. https://doi.org/10.30955/gnj.000376

[14] Barlow, T., Latham, S., Mccrae, I., \& Boulter, P. (2009). A reference book of driving cycles for use in the measurement of road vehicle emissions. TRL Published Project 280. 
http://www.trl.co.uk/online_store/reports_publications/t rl_reports/cat_traffic_and_the_environment/report_a_re ference_book_of_driving_cycles_for_use_in_the_meas urement_of_road_vehicle_emissions.htm $\% 5 \mathrm{Cnhttps}: / / \mathrm{w}$ ww.gov.uk/government/uploads/system/uploads/a

[15] Forester, S., Zero, P., Vehicle, E., By, P., \& September, T. V. (2010). 2010 Subaru Forester Partial Zero Emission Vehicle ( PZEV ) TEST PLAN PREPARED BY eTV September 2009. September 2009

[16] Blondin, J. (2009). Particle swarm optimization: A tutorial....Site:Http://Cs.Armstrong.Edu/Saad/Csci8100 /PsoTutorial...,1-5.

[17] Palupi Rini, D., Mariyam Shamsuddin, S., \& Sophiyati Yuhaniz, S. (2011). Particle Swarm Optimization: Technique, System and Challenges. International Journal of Computer Applications, 14(1), 19-27. https://doi.org/10.5120/1810-2331

[18] Sari, A., Espanet, C., \& Hissel, D. (2008). Particle swarm optimization applied to the co-design of a fuel cell air circuit. Journal of Power Sources, 179(1), 121131. https://doi.org/10.1016/j.jpowsour.2008.01.018

[19] M. Kandi-D, M. Soleymani and A.A. Ghadimi," Designing an optimal fuzzy controller for a fuel cell vehicle considering driving patterns", Scientia Iranica B (2016) 23(1), 218-227

[20] Edwards, P. P., Kuznetsov, V. L., \& David, W. I. F. (2007). Hydrogen energy. Philosophical Transactions of the Royal Society A: Mathematical, Physical and Engineering Sciences, 365(1853), 1043-1056. https://doi.org/10.1098/rsta.2006.1965

[21] Granovskii, M., Dincer, I., \& Rosen, M. A. (2006). Economic and environmental comparison of conventional, hybrid, electric and hydrogen fuel cell vehicles. Journal of Power Sources, 159(2), 1186-1193. https://doi.org/10.1016/j.jpowsour.2005.11.086 http://cs.armstrong.edu/saad/csci8100/pso_tutorial.pdf

[22] Isa, Z. M., \& Rahim, N. A. (2013). PEM fuel cell model parameters optimization using modified particle swarm optimization algorithm. CEAT 2013 - 2013 IEEE Conference on Clean Energy and Technology, 4, 442-445. https://doi.org/10.1109/CEAT.2013.6775672

[23] Salim, R. I., Noura, H., \& Fardoun, A. (2013). A parameter identification approach of a PEM fuel cell stack using Particle Swarm Optimization. ASME 2013 11 th Int. Conf. on Fuel Cell Science, Eng. and Technology Collocated with the ASME 2013 Heat Transfer Summer Conf. and the ASME 2013 7th Int. Conf. on Energy Sustainability, FUELCELL 2013, July. https://doi.org/10.1115/FuelCell2013-18287

[24] Banvait, H., Lin, X., Anwar, S., \& Chen, Y. (2009). Plug-in hybrid electric vehicle energy management system using particle Swarm Optimization. World Electric Vehicle Journal, 3(3), 618-628. https://doi.org/10.3390/wevj3030618

[25] Bhattacharjya, R. K. (2012). Introduction to Particle Swarm Optimization. Indian Institute of Tech, $1-10$. 